\title{
El cooperativismo de trabajo visto desde la perspectiva obrera: apuntes para una nueva ley de cooperativismo de trabajo asociado en Puerto Rico
}

(Workers cooperativism seen from the workers perspective: notes for a new law of associated workers cooperativism in Puerto Rico)

\author{
Rubén Colón Morales ${ }^{1}$ \\ Instituto de Cooperativismo. Universidad de Puerto Rico (Puerto Rico)
}

Sumario: I. Introducción. II. Trabajo Asalariado y Democracia. III. La Alternativa Cooperativista. IV. El Cooperativismo de Trabajo Asociado. V. Cooperativismo y Derechos de Propiedad. VI. Elementos para una Nueva Legislación sobre CTA en Puerto Rico. VII. Conclusión. VIII. Bibliografía.

Summary: I. Introduction. II. Wage Labour and Democracy. III. The Cooperative Alternative. IV. The Associated Workers Cooperativism. V. Cooperativism and Property Rights. VI. Elements to be Considered in a New Legislation on CTA. VII. Conclusion. VIII. Bibliography.

Resumen: El presente artículo persigue identificar las deficiencias presentes en la legislación puertorriqueña sobre cooperativismo de trabajo, y proponer aquellos cambios necesarios para hacerla capaz de promover cabalmente el desarrollo de cooperativas de trabajo asociado (CTA) como una alternativa a los problemas que implica el ordenamiento económico capitalista prevaleciente para la persona obrera. Ello, a partir del análisis e identificación de aquellos elementos inherentes al sistema de trabajo capitalista que deben de ser superados como producto de cualquier legislación que verdaderamente se proponga fomentar la asociación libre y democrática de trabajadores en empresas productivas gestionadas por éstos, superando la condición de trabajadores asalariados.

Palabras clave: trabajo asalariado, contrato de empleo, cooperativas de consumo, cooperativas de trabajo asociado, capital y derechos de propiedad.

1 Instituto de Cooperativismo. Universidad de Puerto Rico. Email: ruben.colon4@ upr.edu 
Abstract: The purpose of this article is to identify the deficiencies present in the Puertorrican workers cooperatives law, and to propose those changes that are required to make such statute a better instrument for the promotion and development of workers cooperatives as an alternative to the difficulties created by the capitalist enterprises for the working class. Such, departing from the analysis and identification of those elements inherently tied to the capitalist work system that has to be overcome as result of any new legislation truly intended to foster the free and democratic associations of worker's in their own productive enterprises.

Keywords: salaried work, employment contract, consumer cooperatives, associated work cooperatives, capital and property rights. 


\section{Introducción}

Puerto Rico cuenta con una Ley General de Cooperativas conocida como Ley 239 de 1 ro de septiembre de 2004 (Ley 239)². Dentro de dicho estatuto general existen 8 artículos particulares que conforman el capítulo 34, mediante los cuales se pretenden reglamentar las cooperativas de trabajo asociado $(\mathrm{CTA})^{3}$. No obstante, en la medida en que dicha Ley General de Cooperativas es una conceptualizada y diseñada para regir cooperativas de consumo, sus disposiciones en muchos sentidos resultan inadecuadas e incluso contradictorias con las disposiciones referentes a las CTA. Esa ausencia de una pieza de legislación específicamente pensada para atender las particularidades del cooperativismo de trabajo y sus diferencias con el cooperativismo de consumo, hace que las CTA carezcan de un marco legal apropiado para su desarrollo en Puerto Rico.

Ante esa situación, buscaremos identificar aquellos elementos que deben incorporarse a la legislación puertorriqueña para poder desarrollar una normativa legal que resulte adecuada para desarrollar el cooperativismo de trabajo. Para ello, partimos del estudio de aquellos elementos inherentes al sistema de trabajo asalariado que deben de ser superados si se busca fomentar empresas productivas autogestionadas democráticamente por sus trabajadores.

\section{Trabajo Asalariado y Democracia}

Al analizar el tema de las CTA desde la perspectiva de la condición obrera, tenemos que comenzar por examinar en qué consiste precisamente esa "condición obrera». Nos referimos al conjunto de circunstancias generales en las que vienen obligadas a laborar regularmente nuestras masas trabajadoras en las empresas capitalistas, en virtud del contrato de empleo. Solo partiendo de un examen de lo que concretamente implica el trabajo asalariado para la clase obrera en términos de su particular posicionamiento dentro de la estructura microeconómica capitalista predominante, y de cómo ello se refleja en sus circunstancias generales de vida; podemos comenzar a definir los atributos con los que idealmente debe contar con una buena legislación para el fomento de cooperativas de trabajo asociado, que provea para transformar esa

25 LPRA sec. 4381 y siguientes.

35 LPRA sec. 4570-4577. 
realidad. Es decir, para poder promover un modelo de legislación que permita a las personas de clase obrera asociarse voluntariamente de forma estable para organizar y operar libremente como trabajadores asociados sus propias empresas productivas, rompiendo con estructuras de explotación, dependencia y subordinación al capital.

Al respecto, tomamos como punto de partida el análisis de lo que significa el trabajo asalariado, a los fines de identificar las características inherentes a dicho régimen que deben ser superadas.

Sabemos que el trabajo obrero es trabajo que se presta en circunstancias contractuales en las cuales el mismo es adquirido por los dueños del capital, quienes, a cambio de pagar a los trabajadores el precio de alquilarles su fuerza de trabajo (el salario); se hacen con el derecho propietario de: i) extraerle el máximo beneficio económico posible para ser distribuido o pagado como rendimiento a la inversión de capital y de ii) controlar el trabajo, incluyendo la toma de decisiones sobre su administración, organización y uso dentro del proceso productivo. De tal modo, en función de sus derechos propietarios sobre el capital, los capitalistas explotan el trabajo con el objetivo de generar el mayor rendimiento posible de sus inversiones monetarias.

De tal forma, una de las principales características que adquiere el trabajo obrero es la de trabajo enajenado. Mediante el contrato de empleo, el trabajador se desprende de su capacidad de trabajo vendiéndola a los capitalistas para que aquellos la apliquen a su antojo sobre los demás factores de producción en la empresa, obteniendo el derecho de apropiarse los resultados finales del proceso productivo. Así, el trabajo obrero no solo se torna ajeno, sino que, además, en la medida en que para vender su fuerza de trabajo los obreros se ven obligados a alquilar sus personas, en el proceso rinden su personalidad pues se les trata como meros portadores de un factor de producción pagado por la clase capitalista. De tal modo, el trabajo asalariado priva regularmente al obrero de la posibilidad de disfrutar experiencias de crecimiento intelectual, aportar iniciativas, procurar su auto realización o expresar su personalidad libremente. Como consecuencia de que el trabajo asalariado se convierte en mercancía para los capitalistas, las personas portadoras de esa fuerza de trabajo se deshumanizan o «cosifican» en ese proceso. En la medida en que la persona obrera: i) pierde la libertad de controlar y expresar su individualidad en el trabajo, ii) labora en circunstancias en las que su fuerza de trabajo transmuta en algo ajeno a su persona, controlada por otros, y iii) dicha dinámica genera la separación entre el obrero y el fruto o beneficio final de su labor (así como del producto mismo elaborado); el trabajo obrero adquiere un carácter esencialmente alienado. En consecuencia, se frac- 
tura el principio de responsabilidad o atribución, al quedar las personas obreras desvinculadas del resultado final de la aplicación de sus fuerzas y capacidades físicas y mentales al proceso productivo; tanto en cuanto al producto mismo, como con respecto de los beneficios generados.

El trabajo obrero también enajena a los trabajadores del resto de sus compañeros, pues típicamente la ingeniería de los procesos productivos tiende a limitar sustancialmente sus interacciones conteniéndolas en procesos mecánicos de producción. Así, el trabajo obrero se torna aislante, condición que interfiere con el establecimiento de relaciones de cooperación o comunitarias desde la perspectiva de los intereses de los propios trabajadores. Además, el trabajo asalariado tampoco suele reconocer el principio de proporcionalidad, pues la ganancia de los inversionistas depende de menospreciar la aportación obrera, mientras se sobrevaloran las aportaciones de la clase empresarial.

Igualmente, tenemos que, por virtud del derecho propietario y contractual aplicable, el trabajo obrero es también de naturaleza subordinada y dependiente. Como sostiene García Müller, los obreros son personas que realizan trabajo de cualquier clase por cuenta ajena y bajo la dependencia de otro, y cuya prestación de servicios es remunerada ${ }^{4}$. Según mencionado, mientras dura la jornada laboral la persona obrera pierde su independencia personal, debiendo utilizar al máximo sus energías y capacidades físicas y mentales a favor del patrono, dentro de un proceso productivo diseñado por los dueños del capital para maximizar la extracción de tales energías. Esa subordinación requiere obediencia de parte de los obreros quienes, a su vez, se conciben como dependientes del capital para poder tener la oportunidad de ganarse la vida. Por cuanto la empresa capitalista está organizada sobre las bases de la tenencia de capital como elemento rector de la producción, los trabajadores se conciben a sí mismos como individualmente reemplazables o prescindibles dentro del proceso productivo. De tal modo, la persona obrera subjetivamente se siente dependiente. Si no se somete a la organización del trabajo diseñada por la clase propietaria, sabe que puede ser sustituida o remplazada por otras trabajadoras que, en igual condición de dependencia frente al capital, para poder laborar, están disponibles para ocupar su puesto de empleo. En la medida en que existe una alta demanda por las plazas de empleo, el precio de comprar la fuerza de trabajo de los obreros (los salarios) se mantiene bajo,

4 García Müller, Alberto; Instituciones de Derecho Cooperativo y de la Economía Solidaria; Editorial Académica Española: Alemania (2012); Tomo I, p. 423. 
y el capitalista tan solo tiene que pagar el mínimo necesario para que sus trabajadores subsistan y repongan sus energías productivas.

De otra parte, en la medida en que los salarios se mantienen bajos, se dificulta la capacidad de los trabajadores de acumular un capital propio, por lo que la clase obrera es una descapitalizada. Y es que si bien el capitalismo ha promovido un incuestionable desarrollo de las capacidades productivas de la espacie humana, la riqueza generada por esa explosión productiva no ha beneficiado a las grandes mayorías trabajadoras, sino que se ha concentrado aceleradamente en manos de un limitado número de personas. Todo lo anterior, como bien reconoce Wolff, no tiene precisamente su base en la forma en que el modelo económico distribuye los recursos a nivel macroeconómico; sino fundamentalmente en la forma en que se organiza la producción a nivel de microeconómico ${ }^{5}$.

En síntesis, nos confrontamos con un mundo de riquezas y recursos extraordinarios acaparados en muy pocas manos, mientras las multitudes trabajadoras subsisten en condiciones de precariedad generalizada, sin verdadero control sobre sus condiciones de vida. En el contexto laboral las personas obreras participan de ese mundo en circunstancias de extrema dependencia dada su incapacidad de controlar sus fuentes de empleo y por su falta de acceso al capital. Los obreros laboran en condiciones de subordinación y explotación en talleres alienantes, estrictamente limitadas en el ejercicio de su personalidad; todo ello en función de la prevalencia de los derechos propietarios de quienes, como dueños del capital, les compran su fuerza de trabajo a precios mínimos.

Esas complejas realidades no pueden ser pasadas por alto si pretendemos promover un modelo de empresa que en realidad responda a los intereses de la clase trabajadora transformando la estructura empresarial de forma tal que se establezca un modelo empresarial liberador, solidario y humano. No olvidemos que el modelo de empresa capitalista imperante en nuestra sociedad, al funcionar sobre un sistema jurídico-económico de primacía del capital sobre el trabajo orientado a la maximización de beneficios al capital por sobre toda otra consideración; genera una ideología social que justifica ese ordenamiento ${ }^{6}$. De

5 Wolff, Richard; Democracy at Work: A Cure for Capitalism; Editorial Heymarket Books; Chicago, USA (2012).

6 Como señala Catalá: «No pasemos por alto que la corporación capitalista moderna ocupa el espacio que ocupa gracias a un marco legal favorable a ella». Cátala, Francisco; Democracia Obrera: ¿Autogestión o Privatización?; Ediciones Huracán, San Juan, Puerto Rico (1996), p.38. 
ese modo, la forma de producción capitalista difunde una cultura que promueve la acumulación de la riqueza socialmente producida, la explotación y el menosprecio de la «mano de obra», el autoritarismo que exige obediencia mecánica y que coarta la libertad individual, la homogeneización limitante de la iniciativa, expresión y autorrealización de los trabajadores y la alienación por la enajenación y desvinculación de los trabajadores respecto del producto y los beneficios de su trabajo.

De tal modo, la polarización en el reparto de la riqueza socialmente producida no solo ha esparcido pobreza, precariedad y una enorme marginación socio cultural a lo largo y ancho de la abusada geografía planetaria; sino que atenta contra las bases mismas del ordenamiento democrático. Cada vez se amplía la tendencia a reconocer mayores derechos políticos a las corporaciones capitalistas para crear opinión, realizar aportaciones electorales y mantener ejércitos de cabilderos en las legislaturas y las principales agencias reguladoras, de forma tal que la democracia política permanece amenazada en cuanto a su sustancia cívica por las grandes corporaciones que cada vez mas controlan la escena política?.

Así, la organización capitalista del trabajo atenta contra el orden democrático en dos dimensiones fundamentales, a saber: i) mediante la promoción en los centros de trabajo de una cultura e ideología de individualismo, apatía, obediencia y dependencia entre las masas trabajadoras (contrarias a la cultura cívica que requiere la vida en democracia), y ii) mediante el control monetario de los procesos democráticos y electorales. Como señala Restakis: "ii]nstitutions that promote selfishness, individualism, competition and dependence on authority have the predictable result of simultaneously isolating and disempowering people» ${ }^{8}$.

Entonces, para poder fundar una economía obrera sobre la base del asociacionismo democrático de los trabajadores, se requerirá generar una nueva cultura de colaboración y solidaridad humana partiendo de la transformación misma de la estructura empresarial, para que la persona humana portadora del trabajo pase a ser el elemento central y primario de los procesos productivos.

7 Para un análisis histórico sobre este particular en el contexto del Estado Norteamericano, véase Parenti, Michael; Democracy for the Few, Editorial Wadsworth Cenage Learning, USA (2011). Igualmente véase. , Winkler, Adam; We the Corporation: How the American Businesses Won Their Civil Rights, Liveright Publishing Co., New York, USA, (2018).

8 Restakis, John; Humanizing the Economy: Cooperatives in the Age of Capital, Editorial New Society Publishers, Canada (2010). 
Si vistos desde la óptica obrera, los valores del modelo prevaleciente de empresa capitalista con fines de lucro se nos muestran adversos y limitantes para el desarrollo de la persona humana y las clases trabajadoras; debemos entonces identificar qué tipo de valores deben orientar la estructuración de empresas cooperativas de trabajo asociado bajo un modelo empresarial verdaderamente transformador.

$Y$ es que, aunque socialmente sostenemos compartir un conjunto de valores ciudadanos que consideramos como fundamentales a una vida mas justa y democrática; nos vemos obligados a renunciar a esos valores en el momento en que entramos por las puertas de nuestros talleres de trabajo y quedamos sometidos a la lógica de la producción capitalista. De tal modo, en el contexto del empleo asalariado aceptamos como forma natural (y prácticamente obligatoria para organizar la producción), una cultura empresarial reñida con los valores sociales que, como ciudadanos pertenecientes a una comunidad política, reconocemos fundamentales para vivir civilizadamente en sociedad. Esa falsa escisión entre el mundo económico y el mundo político evita que nos percatemos de que esa estructura de hacer negocios que son las corporaciones con fines de lucro tiene un específico diseño y contenido jurídico que promueve unos resultados contrarios a los valores que, como ciudadanos, aducimos compartir ${ }^{9}$. Me refiero a los siguientes valores:

1. Libertad - Este valor implica nuestro derecho a desarrollar, afirmar, defender y expresar (incluso mediante preferencias asociativas) nuestra individualidad personal, de la forma mas amplia posible.

2. Democracia - Implica nuestro derecho de participar en la toma de aquellas decisiones que nos afectan. Si el resultado de un proceso decisional colectivo nos va a vincular o a afectar, entonces debemos tener derecho a participar del mismo, y mientras mayor sea el impacto sobre nosotros de las determinaciones que se tomen, mayor debe ser nuestro derecho de incidir.

3. Igualdad - Como principio general, todas las personas deben gozar de los mismos derechos y deben tener iguales accesos a similares oportunidades. Este principio incluye el derecho de no discriminación arbitraria.

9 Para una discusión detallada de éstos asuntos véase: Dhal, Robert, A.; A Preface to Economic Democracy; University of California Press; USA (1985). 
4. Reciprocidad - Este principio plantea la obligación de tratar con justicia («fairness»), equidad o proporcionalidad a las personas en atención a sus necesidades, capacidades y aportaciones, en aquellos procesos que conllevan una retribución o distribución de beneficios. Se relaciona directamente al concepto del mérito.

5. Responsabilidad - Las personas deben responder por sus actos y asumir las consecuencias tanto positivas como negativas de los mismos. Este principio se relaciona directamente a conceptos legales como los de atribución e imputabilidad.

6. Fraternidad - Principio que plantea que los seres humanos tienen responsabilidades generales unos con otros, por lo que se deben colaborar y apoyarse mutuamente. Los valores de solidaridad, cooperación, caridad, altruismo y amor al prójimo, se relacionan a este principio.

7. Eficiencia - Principio que plantea la utilización de nuestros limitados recursos de la mejor forma posible, en función maximizar resultados en distintos ámbitos, con el menor consumo posible de recursos.

Sostenemos que la única manera de hacer compatibles esos principios democráticos socialmente compartidos con la operación de las empresas, es emancipar a los trabajadores de su subordinación al capital mediante mecanismos de coparticipación y cogestión empresarial. En cuanto a lo anterior, coincidimos con Iturraspe ${ }^{10}$ en el sentido de que una nueva visión del trabajo y la seguridad social tiene que incorporar el enfoque de derechos humanos haciendo énfasis en convertir al trabajador en un ciudadano de la empresa y actor fundamental, antes que en el objeto de la regulación.

Si estamos en lo correcto respecto de que los referidos valores ciudadanos los consideramos como esenciales para una saludable vida social, entonces debiéramos procurar identificar formas de organizar la producción mediante empresas que operen conforme a los mismos; en vez de sacrificarlos en pos pretender aumentar estrictamente el beneficio del capital en la operación de las empresas. Ello, a menos de que la experiencia histórica nos dicte que no existe otra manera de organizar la producción eficientemente de forma tal que podamos satisfa-

10 Iturraspe Oviedo, Francisco; Incorporación de la idea de Derecho Social y del Derecho Internacional de los derechos humanos al análisis de nuestro tema. Publicado en Fajardo García (Coordinadora); Empresas Gestionadas por sus Trabajadores Problemática Jurídica y Social; Ed. CIRIEC España (2015), p. 167. 
cer nuestras necesidades humanas y nuestras aspiraciones de progreso colectivo, que no sea la empresa capitalista. No obstante, los estudios realizados tienden a demostrar que no existe data empírica que nos permita concluir que la empresa capitalista tiene que ser necesariamente mas eficiente que empresas que puedan ser democráticamente gestadas por sus trabajadores, sino mas bien, al contrario ${ }^{11}$.

De hecho, ya desde 1840 John Stuart Mill, convencido de que las empresas manejadas por los trabajadores contaban con mayor capacidad para la eficiencia, equivocadamente predijo que éstas se convertirían en la forma predominante de producción en nuestros tiempos. Al respecto Mill sostuvo que:

«... si la humanidad continúa progresando, la forma de asociación que es de esperar predomine en definitiva no es la que puede existir entre un capitalista que actúa como jefe y un obrero que no tiene voz ni voto en la dirección, sino la asociación de los mismos trabajadores en condiciones de igualdad, poseyendo colectivamente el capital con el cual realizan sus operaciones y trabajando bajo la dirección de personas que ellos mismos nombren y destituyan» ${ }^{12}$.

Lo anterior, según Mill, no era de esperarse que los trabajadores estuviesen dispuestos a trabajar por siempre de forma asalariada como su condición de vida, y puesto que claramente las empresas manejadas por trabajadores les ofrecían las siguientes ventajas: 1) promueven la autorealización a través del trabajo significante, convirtiendo la ocupación diaria de cada persona en escuelas de lazos sociales e inteligencia práctica; 2) las empresas serían mas eficientes y productivas debido a que generarían en los trabajadores el interés de aportar al máximo para obtener mayor remuneración, pues la disciplina sería autoimpuesta en beneficio colectivo y no a conveniencia de un patrono con intereses encontrados a los de los trabajadores; y 3) habilitarían a los seres humanos a trabajar unos con otros en relaciones no de dependencia, sino

11 Véase: Capítulo 1: Empresa y Trabajo en Cátala, Francisco; Democracia Obrera: ¿Autogestión o Privatización?; Ediciones Huracán, San Juan, Puerto Rico (1996). También, Perotin, Virginie; The Performance of Worker's Cooperatives, Capítulo 8 en The Cooperative Business Movement: 1950 to the Present, Battilani y Schorter, Editores; Cambridge University Press, USA (2012). También, The Competitive Sucess of WSDEs, Capítulo 10.1 en Wolff, Op. Cit. y Capítulo 2: Is Worker-Ownership Efficient?, en Pinto, Sanjay; Ours To Share: How Worker- Ownership Can Change the American Economy; Surdna Foundation; https://philantropynewyor.org/sites/default/files/resources/ OursToShareWeb1.pdf. Además, Birchall and Ketilson, Resilece of the Cooperative Business Model in Times of Crises, International Labor Organization, (2009).

12 Catalá Francisco, Op. Cit, p. 68-68. 
promoviendo la democracia, tanto a nivel de la sociedad como de las empresas, pues tales talleres requerirían de mecanismos de autogobernanza ${ }^{13}$.

\section{La Alternativa Cooperativista}

Si no podemos concluir que las empresas capitalistas por naturaleza son necesariamente mas eficientes que las empresas de trabajadores, debiéramos entonces cuestionarnos la aceptación de ese modelo como la forma principal para la operación de empresas en una economía de mercado, particularmente considerando que su cultura organizacional contradice nuestros valores democráticos. Por el contrario, lo razonable sería promover que esos valores que compartimos como ciudadanos sean extendidos y reconocidos en todos los ámbitos de la actividad humana, incluyendo las empresas productivas.

¿Cómo entonces proponer vías alternas para estructurar el quehacer económico con las que podamos satisfacer nuestras necesidades y aspiraciones de progreso material sin comprometer nuestros valores humanistas? ¿Cómo promover un tipo de empresarismo obrero capaz de promover la eficiencia y el progreso económico de forma continua y sustentable en función del mayor bienestar general de las personas?

Sin duda, el cooperativismo es una alternativa que ha demostrado su eficiencia empresarial a la misma vez que se sostiene sobre valores positivos de libertad, democracia, igualdad, responsabilidad, reciprocidad y fraternidad, sin menoscabar el principio de eficiencia. Las cooperativas forman parte de la economía solidaria, la cual abarca al «conjunto de entidades que actúan en el mercado con la finalidad de producir bienes y servicios, asegurar o financiar, donde la distribución del beneficio y la toma de decisiones, no están directamente relacionadas con el capital aportado por cada socio, y donde cada socio puede participar por igual en la toma de decisiones» ${ }^{14}$.

13 Las referencias a la obra de Mill son tomadas del trabajo de Shuartz, Justin; Where Did Mill Go Wrong?: Why the Capital-Managed Firm Rather than the Labor-Managed Enterprise Is the Predominant Organizational For in Market Economies; 73 Ohio State Law Journal p.219 (2012).

14 Herández Perlines, Felipe; La Economía Social, análisis de un sector empresarial, en La Economía Cooperativa como Alternativa Empresarial, Ediciones de la Universidad de Castilla La Mancha, España (2010), p. 137. 
Las empresas cooperativas operan dentro de un sistema de libre mercado con independencia frente al Estado, procurando operar con alta eficiencia y productividad pero para beneficio de sus socias. Dicha gestión empresarial cooperativa se enmarca dentro de los márgenes de ciertos conceptos filosóficos de centralidad de la persona humana, democracia organizacional, limitación de beneficios al capital y responsabilidad social. En ese sentido, el cooperativismo no procura ser un empresarismo «neutral» sino uno axiológico, que promueve valores éticos consistentes con aquellos que socialmente sostenemos compartir.

Ahora bien, no todo tipo de cooperativismo opera igual. Existen marcadas diferencias entre las formas de operar de un cooperativismo de consumo producto del asociacionismo entre consumidores, y el tipo de cooperativismo organizado por los trabajadores de una empresa. Reconocer las diferencias y dinámicas propias de cada uno resulta de cardinal importancia a la hora de fomentar el cooperativismo de trabajo asociado, pues su lógica operacional distinta requiere de una normativa legal que se ajuste a ella, en vez de a la naturaleza distinta, las cuales no siempre encajan dentro de la normativa aplicable a las cooperativas de consumo.

\section{El Cooperativismo de Trabajo Asociado}

El cooperativismo de producción se fundamenta en un modelo de trabajo asociado en el cual varias personas se unen para organizar y operar democráticamente una actividad productiva, con el ánimo de repartirse equitativamente (en proporción a la asignación de valor determinada por éstos al trabajo aportado por cada cual) los beneficios económicos resultantes de la venta en el mercado de los bienes o servicios producidos en común. El fin que persiguen los socios al unirse en una CTA es la creación y preservación de plazas de trabajo mediante la operación de una empresa productiva de gestión colectiva. Así, cada trabajadora auspicia la cooperativa aportando sus capacidades y fuerzas productivas en la elaboración de los bienes que la cooperativa vende en el mercado; a cambio de la facultad de participar de la gobernanza democrática de la empresa sobre bases de igualdad, así como del derecho de participar proporcionalmente de la distribución de sus resultados económicos. Al respecto señala Verón:

"La cooperativa de trabajo es una modalidad o especie de cooperativa organizada por y para los trabajadores de cualquier actividad laboral permanente, persiguiendo, por lo general, una mejor valo- 
ración del tiempo, para lo cual se organizan empresarialmente aportando capital y esfuerzo personal que emplean, en conjunto, y como labor o trabajo asociado, para la concreción del objeto social» ${ }^{15}$.

\section{Por su parte Costas Comesaña añade ${ }^{16}$ :}

"Con carácter general, la diferencia esencial entre una CTA y el resto de clases de cooperativas radica en la actividad cooperativizada: la prestación del trabajo personal de los socios. En consecuencia, la definición de las CTA que contienen las leyes de cooperativas (que debe ser complementada con el concepto legal de cooperativa y con los principios cooperativos formulados por la Alianza Cooperativa Internacional, bascula entorno a la idea de la cooperativización del trabajo personal del socio, para producir en común bienes o servicios para terceros (para el mercado), que permitan satisfacer sus necesidades o aspiraciones laborales; de todos o algunos de los socios, simultáneamente o con carácter estacional, a tiempo completo o parcial, con carácter indefinido o temporal. En definitiva, se puede sostener que la obtención, mantenimiento o mejora de un puesto de trabajo remunerado constituye la renta, causa o finalidad mutualista de la CTA, mientras que su objeto es la organización cooperativa de la prestación del trabajo personal».

Según antes mencionado, distinto a otros tipos de cooperativas, en las CTA la relación con sus socios no es una de consumo sino de producción. Los socios de la CTA no son clientes de los servicios o productos que vende la cooperativa, sino que son quienes los producen para entonces ser vendidos por la cooperativa a terceros. Por tanto, en las CTA el acto cooperativo entre socios y cooperativa se desenvuelve de forma distinta a las dinámicas empresariales que tienen lugar en el contexto del cooperativismo de consumo. Se trata de un aspecto importante, cuyas repercusiones muchas veces no son debidamente ponderadas.

Ciertamente, en la medida en que en toda cooperativa bona fide es gobernada democráticamente en función de los derechos personales de membresía de las socias bajo el principio de una persona un voto, y dado que la distribución de rendimientos no se efectúa en atención a la cantidad de capital aportado sino en función del vo-

15 Verón, Alberto V.; Tratado de las Cooperativas; Editorial La Ley; Buenos Aires, Argentina; 2009; Tomo III, p. 316-317.

16 Costas Comesañas, Julio; Cooperativas de Trabajo Asociado, p. 1210, Capítulo XV, Tomo II, en Peinado Gracia y Vázquez Ruano; Tratado de Derecho de Cooperativas, Ed. Tirant Lo Blanch, Valencia (2013). 
lumen de actividad económica efectuada por cada cual con la cooperativa en torno de la actividad cooperativizada (el patrocinio); en todas las empresas cooperativas el capital pierde el papel predominante y definitorio del que goza en las empresas capitalistas. No obstante, si bien en las cooperativas de consumo el capital pierde gran parte de su dominio sobre la actividad empresarial, ello no significa que se haya abolido el elemento de la subordinación del trabajo al capital. Y es que el cooperativismo de consumo plantea un sistema de democracia entre consumidores en el cual pueden subsistir relaciones de explotación con respecto al trabajo, reproduciéndose circunstancias laborales similares a las de las empresas capitalistas. En ese sentido la diferencia de éstas con las empresas de capital radica en que en las cooperativas de consumo los beneficios generados por la subordinación del trabajo se redistribuyen a los socios consumidores, en vez de ser apropiada por inversionistas externos. Sin embargo, siempre existirá una parte del beneficio derivado por los socios de las cooperativas de consumo que responda a la apropiación por éstos del valor excedente del trabajo generado por los empleados de la cooperativa.

Moirano explica claramente la diferencia entre el concepto del excedente en el contexto de ambos tipos de cooperativas:

«[Como la cooperativa [de consumo] desarrolla una actividad económica de servicio y no de lucro, el sobrante que pueda resultar al finalizar el ejercicio social no es ganancia sino un excedente, que resulta del uso del servicio cooperativo y se trata, simplemente, de un error en el cálculo de los costos de la actividad económica de la entidad [incluyendo el del trabajo]. Pero no se trata no de un error voluntario, sino que es resultado de la imposibilidad de calcular con exactitud todos los costos de la gestión social. Cabe advertir, sin embargo, que este concepto no es aplicable a las cooperativas de trabajo en lo que hace al resultado del ejercicio....

En las cooperativas de trabajo este procedimiento se realiza devolviendo ese sobrante a los asociados en proporción a lo percibido a lo largo del ejercicio, porque ese sobrante en una empresa común hubiera sido la ganancia del empresario, cuya intermediación la cooperativa ha suprimido ... En las demás cooperativas, esta devolución se hace en proporción de lo pagado o recibido por cada uno por la adquisición o venta de bienes o servicios, porque el excedente indica que pagaron en exceso o recibieron de menos» ${ }^{17}$.

17 Moirano, Armando Alfredo; Manual de Cooperativas de Trabajo; Editorial Lajouane; Buenos Aires, Argentina (2010), p. 16-17 
Así, contrario a una cooperativa de consumo donde el producto que se ofrece coincide con la necesidad que buscan satisfacer sus socios; en las de trabajo el fin de las socias es procurarse fuentes de empleo mediante la venta de los servicios o productos de la cooperativa a terceros. En ese sentido, las economías netas de las cooperativas de trabajo no se pueden entender como excedentes cobrados de mas a sus socias, sino como ganancias pagadas de menos a los trabajadores por su aportación de valor a la empresa. Esto es, en la cooperativa de consumo el resultado final de la ecuación económica es la devolución de lo pagado en exceso por los socios en atención al volumen de bienes adquiridos por estos de parte de la cooperativa; por lo que, en síntesis, se trata de restablecer la ecuación costo = servicio (siendo el trabajo considerado como parte de los costos). No obstante, en las de producción el propósito es la distribución entre los trabajadores de los resultados (positivos y negativos) del proceso productivo ${ }^{18}$. Como nos recuerda Costas Comesañas, el ideal obrero de la emancipación de los trabajadores frente al patrono es un elemento que ha estado en el origen de muchas cooperativas de trabajo ${ }^{19}$.

Otra diferencia que cabe puntualizar es que en las cooperativas de consumo, se pueden proveer los bienes objeto de la actividad cooperativizada a terceros no socios, sin que ello atente necesariamente contra su naturaleza. En sentido contrario, en las de producción la aportación de los socios (su trabajo) es de naturaleza personalísima, indelegable e indispensable, y no es posible que terceros no socios participen del objeto de la actividad cooperativizada sin que ésta corra el riesgo de perder su naturaleza o esencia empresarial20. Ello así, pues se trata de una estructura que pretende reivindicar la centralidad del trabajo como elemento dominante de la producción, por lo que, excepto por razones de necesidad expresamente limitadas, no le es dado a las CTA tener empleados contratados a sueldo, excluidos del derecho a ser socios y de participar así tanto de su gestión, como de la distribución de beneficios.

Consideramos imprescindible puntualizar tales diferencias entre el cooperativismo de trabajo y el consumo pues los principios y prácticas elaboradas para las últimas contenidas en las leyes de cooperativismo en Puerto Rico, no necesariamente satisfacen las necesidades de las primeras. Como señala Moirano:

\footnotetext{
18 Moirano, Op. Cit., p. 17

19 Costas, Comesañas, Op. Cit., p. 1208.

20 Véase Moirano, Op. Cit., p. 28.
} 
«[l]os principios de la cooperación ... si bien son de aplicación para todas las cooperativas incluidas las de producción o trabajo, resultan insuficientes para éstas últimas, porque presentan características propias que las distingue del resto ${ }^{21}$.

En ese sentido, reconoce el citado autor que los principios distintos del cooperativismo de trabajo fueron establecidos desde la publicación del tratado de Philippe Buchez sobre el tema, en 1831. En el mismo, Buchez reconoció los siguientes principios particulares aplicables a las cooperativas de trabajo:

1. Los asociados se constituirían en empresarios; a estos efectos, erigirán entre ellos a uno o dos representantes que tendrán la firma social.

2. Cada uno de ellos continuará cobrando un salario según los usos adoptados en la profesión, es decir, por jornal o tarea, y según la habilidad individual.

3. Una cantidad equivalente a lo que los empresarios intermediarios descuentan cada jornada, se reservará; a fin de año, esa cantidad que será el beneficio neto, se repartirá de la forma siguiente: $20 \%$ para formar y aumentar el capital social; el resto se empleará en socorros o se distribuirá entre los asociados a prorrata de su trabajo.

4. El capital social, que irá aumentando, por lo tanto, cada año en una quinta parte de los beneficios, será inalienable; pertenecerá a la asociación, que será declarada indisoluble, no porque los individuos no puedan darse de baja de ella, sino porque dicha sociedad se habrá hecho perpetua con la admisión continua de nuevos miembros.

5. La asociación no podrá hacer trabajar por su cuenta a obreros extraños durante mas de un año; pasado ese tiempo estará obligada a admitir en su seno al número de trabajadores nuevos que se hubieran hecho necesarios por el aumento de sus operaciones ${ }^{22}$.

El reconocimiento de tales diferencias entre las CTA y el cooperativismo de consumo lleva necesariamente a la conclusión de que la reglamentación jurídica de las CTA requiere de disposiciones legales específicamente diseñadas pensando en éstas. Por esa razón, nuestra legislación puertorriqueña en la cual se insertan 8 artículos sobre coo-

21 Moirano, Op. Cit., p 22.

22 Véase Moirano, Op. cit., p. 24-26. 
perativismo de trabajo dentro de una ley conceptualizada para regir cooperativas de consumo, constituye un error conceptual jurídicamente inapropiado para fomentar cabalmente el desarrollo de las CTA.

\section{Cooperativismo y Derechos de Propiedad}

El cooperativismo de trabajo se aparta tanto del control autoritario y del acaparamiento de los beneficios del proceso productivo que ejerce el capital en la economía capitalista, como del que ejerce el gobierno en las economías estatizadas. Al respecto, el cooperativismo de trabajo reconoce que a nivel microeconómico, en ambos sistemas los derechos de propiedad sobre el capital dominan el factor trabajo ${ }^{23}$. A nivel empresarial en ambos contextos el derecho de propiedad sobre los medios de producción continúa subordinando al trabajo y reclamando el derecho de organizar la producción y de apropiarse de los beneficios; aunque en las economías estatizadas se plantee que esos beneficios luego son socialmente redistribuidos.

Como señala Pencavel:

Although worker cooperatives vary considerably, they have two key features that relate to ownership and to management. Ownership can mean many things, but it usually connotes the right of a body of individuals to receive any positive residual of gross revenues over costs. In the worker co-op, all or some of the people who work in the Enterprise have this right. As for management, in a worker coop, all or some of the people who work in the Enterprise have the right to make crucial workplace decisions or to choose directly those who makes this decisions ${ }^{24}$.

En sentido distinto, el cooperativismo de trabajo buscar subvertir la relación entre capital y trabajo presente tanto en las empresas capitalistas como en la estatizadas, y que responde a una construcción similar de los derechos de propiedad. De tal modo, en las CTA ocurre una descomposición del derecho de propiedad capitalista. En el régimen de trabajo asociado se altera la ecuación, y entonces es el trabajo asociado el que alquila al capital y le paga un rendimiento limitado en función de su costo como factor de producción. Así, se sustraen del derecho de

23 Véase Wolff, Op. cit., capítulo 5: The Major problems of State Capitalism.

24 Pencavel, John H., editor; The Economics of Workers Cooperatives; Editorial Edward Elegar Publishing Limited; Great Britain (2013) (p. xi). 
propiedad sobre el capital los atributos de gobernar la empresa y de reclamar los beneficios de la operación; pues los mismos se adhieren indisolublemente a la condición de ser socio trabajador de la cooperativa. Como señala Ellerman, las empresas democráticas de trabajadores trabajan a base de los siguientes fundamentos:

The theory of democratic worker-owned firms walks on two legs. That is, it rests on two principles. (1) The property structure of the democratic firm is based on the principle that people have a natural and inalienable right to the fruits of their labor [; and] (2) The governance structure of the democratic firm is based on the principle that people have a natural and inalienable right to democratic self-determination ${ }^{25}$.

De tal modo, en las empresas de trabajo asociado se abole el contrato de empleo mediante el cual el capital alquila al trabajo (al colocarse la clase empresarial como intermediaria entre ambos); para dar paso a una relación mediante la cual es el trabajo el que alquila el capital, suprimiendo la intermediación de la clase capitalista. Al abolirse el contrato de empleo, el derecho a organizar la producción y a reclamar el resultado del beneficio recae entonces en los trabajadores como colectivo, en su carácter dual de miembros de la entidad asociativa y de trabajadores. Eso significa que los derechos de gobernanza sobre la empresa se le adscriben a los trabajadores en función de su condición de miembros de la comunidad asociativa existente entre ellos y sobre bases democráticas de una persona un voto. En cuanto a la distribución de beneficios, la misma se atribuye al conjunto de los trabajadores que se la distribuyen en función de la proporción de unidades de trabajo aportadas por cada cual, a base de criterios de calidad y cantidad. Como nuevos responsables de la producción, los trabajadores tienen que asumir tanto las consecuencias positivas como negativas de su gestión, a tenor con el principio de responsabilidad.

De tal modo, en una CTA no es una condición necesaria que los trabajadores asociados tengan que ser propietarios del capital, después de que se establezca la condición jurídica de que el capital está subordinado al trabajo. Para ello, lo que se abole es el contrato de empleo, pudiendo de ese modo el trabajo arrendar el capital y pagar su precio justo de mercado (interés limitado), sin necesidad de ser sus propietarios. Como añade Ellerman:

25 Ellerman, David; The Democratic Worker -Owned Firm: A New Model For East and West; Unwin Hyman Publications; London (1990), p. 9. 
A conventional corporation only takes on an authority relation over people when it hires them as employees... Thus, democratic rights require not the abolition of the private ownership but of the employment contract. They require that conventional corporations not be abolished but only «depopulated» as a result of the abolition of the employment relation. To be employed productively, the assets would have to be leased to a democratic firm.

The reversal of the contract between capital and labor (so that labor hires capital) could also take place by internally restructuring a capital corporation as a democratic firm with the old shareholders' securities being restructured as participating debt securities ${ }^{26}$.

Puntualiza Ellerman que en las empresas capitalistas los dueños del capital controlan la gestión económica como una extensión de su derecho de propiedad, en función de la relación jurídica que se crea entre el capital y trabajo que permite al primero contratar a los trabajadores asalariadamente ${ }^{27}$. Tal planteamiento no se distancia mucho de los principios elaborados por Buchez, al establecer necesidad en las CTA fueran los trabajadores los que asumieran el papel del empresariado como regidores de la producción.

De tal modo, en una empresa de trabajo asociado el aspecto determinante no sería el que los trabajadores tengan que ser propietarios del capital, sino el que no laboren en circunstancias de subordinación y de dependencia con respecto del mismo. Ello se consigue mediante la eliminación del contrato de empleo organizando la empresa de forma tal que la fuerza de trabajo sea la que utilice el capital para su beneficio, según democráticamente lo determine el colectivo de trabajadores. Al ser los trabajadores colectivamente quienes contratan el capital, se produce un giro de 180 grados en la operación de la empresa. Una vez el capital deja de ser el elemento rector de la empresa y pasar a serlo el trabajo, entonces tanto la gobernanza como la distribución de beneficios tienen como fundamento el trabajo y la relación asociativa entre quienes lo aportan. Como bien señala Acuña ${ }^{28}$.

«... uno de los desarrollos mas proficuos que admite el concepto de acto cooperativo, está vinculado a la subordinación de las relaciones

26 Ellerman, Op. Cit, p. 64-65.

27 Ellerman, Op. Cit., p 68.

28 Acuña, Mónica A.; El acto cooperativo y su contribución a la naturaleza jurídica de las cooperativas de trabajo. Publicado en Publicado en Fajardo García (Coordinadora); Empresas Gestionadas por sus Trabajadores Problemática Jurídica y Social; Ed. ClRIEC España (2015), p. 175-176 
contractuales de él nacidas, en la relación principal que es la participación asociativa, que la condiciona y de la cual no puede desvincularse.

Relación que vincula al trabajador asociado, con su nexo de origen y que configura su status de asociado y no de trabajador en relación de dependencia, aspecto este absolutamente soslayado de la jurisprudencia laboral.

Las CTA son entidades formadas por trabajadores que se asocian con el propósito de obtener o mantener ocupación de trabajo.

Se trata pues de organizaciones democráticas de los propios trabajadores en las que todos los asociados participan en pie de igualdad en la toma de decisiones no configurándose, las notas de subordinación técnica (todos los asociados determinan sus condiciones de trabajo) jurídica (los mismos asociados son los dueños de la empresa) y económica (los asociados comparten el riesgo económico empresario) que caracterizan al vínculo laboral. Por el contrario, resulta que se trata de una relación asociativa incompatible con dicho vínculo.

En definitiva, otra forma de trabajo que no es el trabajo en relación de dependencia, ni autónomo, sino autogestionado, no reconocido por la mayoría de la doctrina autoral y judicial laboral, formada en la disciplina protectora del trabajo» ${ }^{29}$.

\section{Al respecto añade Collazo:}

«El autogestionismo, por su parte, está basado en la soberanía del trabajador y su control democrático de la empresa como socio y empresario colectivo, independientemente de su aportación de capital. En su forma mas pura, la empresa autogestionaria excluye a los dueños del capital de toda participación en la toma de decisiones, de la misma manera que la empresa capitalista lo hace con el trabajador» ${ }^{30}$.

De tal modo, las CTA operan sobre principios de democracia participativa donde los trabajadores asociados determinan los rumbos de la actividad empresarial conforme al principio de una persona un voto, con total independencia cualquier grado de participación en el capital de la empresa. Es en función de esa participación que colectivamente

29 Acuña, Mónica A.; El acto cooperativo y su contribución a la naturaleza juridica de las cooperativas de trabajo. Publicado en Fajardo García (Coordinadora); Empresas Gestionadas por sus Trabajadores Problemática Jurídica y Social; Ed. CIRIEC España (2015), p. 175-176.

30 Collazo, Fernando; La Economía del Autogestionismo Empresarial: Competitividad, Solidaridad y Democracia en la Era de la Globalización. Editorial Impresive Publications LLC, Puerto Rico (2018) p. 143. 
le adscriben valor a las aportaciones de trabajo de cada cual. De ese modo, el cooperativismo de trabajo opera en cuanto a sus aspectos de gobernanza de forma consistente con nuestros valores sociales de libertad, igualdad y democracia; mientras que las empresas de capital los descartan al operar en consideración exclusiva a la tenencia de riqueza individual. De otra parte, al distribuir los frutos de la operación económica a los trabajadores en atención a la cantidad y calidad del trabajo aportado por cada cual, el trabajo asociado responde a los valores de reciprocidad, responsabilidad y eficiencia antes discutidos.

Cabe destacar que el derecho a reclamar los frutos del trabajo propio, así como el de la gobernanza democrática, son complementarios en el contexto del trabajo asociado. Ello así, tal y como señala Gould ${ }^{31}$, porque de ordinario en los talleres de trabajo colectivo (principalmente de naturaleza industrial), resulta muy difícil poder identificar las aportaciones individuales de cada cual respecto del producto final. Por tanto, en tales circunstancias los procesos de gobernanza democrática resultan fundamentales para garantizar el derecho de cada cual a los frutos de su propio trabajo, lo cual se determina mediante la participación de todos los socios en la toma de decisiones al respecto.

Al suprimirse el contrato de empleo, el factor trabajo asume la función de empresario y con ello todas las responsabilidades que en la empresa capitalista ejercen éstos. En cuanto a dicho particular, en tanto y en cuanto uno de los principales atributos del empresario capitalista es organizar la prestación del factor trabajo, en las CTA los trabajadores deben evitar que el manejo de los asuntos de personal se convierta en una replica de estilos de administración capitalista. Esa nueva administración debe conceptualizarse e implementarse por medios participativos de naturaleza no adversativa ni punitiva, sino que fomenten y potencien la cooperación entre trabajadores proveyendo experiencias de capacitación, crecimiento y satisfacción personal. En ese sentido, no solo los procesos administrativos y disciplinarios deben ser revaluados, sino también los mecanismos de resolución de disputas, los cuales deberán ser cónsonos con la naturaleza distinta de las CTA ${ }^{32}$. En consecuencia, es imprescindible fortalecer el elemento de la educación cooperativa y la capacitación empresarial de todos los trabajadores como

31 Gould, C.C.; Rethinking Democracy; Cambridge University Press, New York (1988), p. 153-157.

32 Ordeñana Gezuraga, Ixusko; Mas allá del arbitraje cooperativo: la mediación cooperativa. Sobre la necesidad de fomentarla en el ordenamiento jurídico español a la luz del Real Decreto -Ley 5/2012, de 5 de marzo, de mediación en asuntos civiles y mercantiles; 8 GEZKI 2012, p 111-141. 
elemento esencial para conseguir transformar las relaciones de trabajo en las CTA, diferenciándolas de aquellas predominantes en las empresas capitalistas.

\section{Elementos para una Nueva Legislación sobre CTA en Puerto Rico}

A partir de todo lo anterior, sostenemos que la legislación puertorriqueña sobre CTA es una insuficiente a los fines de promover el desarrollo de estas empresas autogestionadas. Se requiere mucho trabajo de conceptualización para atemperar la legislación vigente a las dinámicas propias y naturaleza particular del cooperativismo de trabajo asociado. Por tanto, sostenemos la necesidad de fomentar legislación para el desarrollo de las CTA mediante una nueva ley concebida especialmente para éstas, separadas del estatuto general de cooperativas existente.

Como ya hemos establecido, existen importantes diferencias entre ambos tipos de cooperativas por lo que la normativa aplicable al cooperativismo de consumo se queda corta a los fines de establecer un marco jurídico adecuado para el funcionamiento del cooperativismo de trabajo. Por ello, necesitamos elaborar una nueva ley que, sin dejar de lado los principios generales del cooperativismo, pueda proveer un marco jurídico que atienda la distinta naturaleza y tipo de gestión de negocios de las CTA. La centralidad del trabajo como elemento determinante y primario, la abolición del contrato de empleo y la particular naturaleza del acto cooperativo en ese contexto, deben quedar expresamente reconocidos como parte de cualquier esfuerzo legislativo que se proponga promover las CTA.

Similarmente, debemos reconocer que los principios universales del cooperativismo, si bien continúan resultando de aplicación general a las CTA, adquieren connotaciones distintas en el contexto de estas. Por ejemplo, el principio de adhesión libre y voluntaria plantea unos problemas particulares en el contexto de las cooperativas de trabajo que no suelen estar presentes en el ámbito de las cooperativas de consumo. Ello así, pues las CTA lidian con unas relaciones entre socios de carácter mas íntimo, profundo e interdependiente, que los que implican en el contexto de las cooperativas de consumo. De otra parte, la libre adhesión tiene que tener límites relacionadas a la capacidad de la empresa de garantizar plazas de empleo estables y permanentes.

Igualmente, el principio de control democrático adquiere dimensiones totalmente distintas en el contexto de las cooperativas de tra- 
bajo con respecto de las de consumo, en vista de ese tipo de relaciones mas hondas que se generan al interior de las CTA. Y es que la interacción continua y cotidiana entre sus miembros y las implicaciones de las decisiones de la cooperativa en la vida de sus socias, como norma general será mas intensa en las CTA. En ese sentido, los mecanismos asamblearios anuales que son utilizados por las cooperativas de consumo bajo nuestra legislación cooperativa, no resultan suficientes para atender las dinámicas propias del cooperativismo de trabajo. Por eso postulamos la necesidad de establecer comités de diálogos mas o menos permanentes con carácter menos formal y mucho mas regular que las típicas asambleas anuales, como lo es la Comisión de Miembros reconocida en la legislación de Quebec. Se trata de un cuerpo de gobernanza cooperativa que se constituye como asamblea permanente y que concentra la totalidad de las funciones deliberativas, directivas e incluso ejecutivas de las cooperativas de trabajo ${ }^{33}$. Similarmente, la ley de California sobre corporaciones democráticas de trabajadores reconoce la posibilidad de establecer un órgano deliberativo y directivo permanente ${ }^{34}$. Entendemos que nuestra legislación debiera proveer para que al menos en cooperativas con un número limitado de miembros se pueda establecer un mecanismo de asamblea permanente para la toma de decisiones cotidianas por todos los trabajadores.

De otra parte, entendemos que dada la naturaleza de la relación entre las socias de una cooperativa de trabajo, se impone la necesidad de incorporar mecanismos internos no adversativos ni punitivos de resolución de conflictos, en vez de delegar la resolución del conflicto a terceros que se posicionan sobre las partes en conflicto (supra partes), en vez de entre aquellas (inter partes) ${ }^{35}$. Al respecto, la mediación y la intervención de amigables componedores debieran ser requeridos previo a cualquier utilización de mecanismos adversativos o de adjudicación por terceros. En cuanto a ese aspecto, la resolución de conflicto en las CTA debieran procurar el objetivo de restituir o sanar el espíritu de cooperación, en vez de promover la victoria de una parte sobre otra con la correspondiente generación de círculos viciosos de luchas vengativas. No nos parece objeto de mucha discusión reconocer que en todo tipo de relaciones humanas existe la posibilidad de conflicto y que mientras mas íntimas, continuas y directas sean esas relaciones, mayor es el potencial de conflicto y mayores también las consecuen-

\footnotetext{
33 Véase García Müller, Op. Cit.

34 https://leginfo.legislature.ca.gov/faces/billNavClient.xhtml?bill_id=201520160AB816

35 Ordeñana Gezuraga; idem. p. 117.
} 
cias de no resolverlos amistosamente. La incorporación de procesos de medición en el contexto de las CTA es recomendado por Ordenana quien señala:

«[L]a mediación es la forma natural y próxima a los contendientes para la solución del conflicto; es un instrumento de cooperación entre las partes, que confían en la ayuda de un tercero imparcial para solventar su disputa de manera no agresiva, sin imposiciones ni venganzas. Para ello, es labor del tercero auxiliar a las partes de la disputa, impulsando una negociación que haga que aquellos dejen de ser enemigos y contrincantes para convertirse en cooperantes, intentando que con su propio esfuerzo lleguen al acuerdo que ambos necesitan. Con todo pues, la mediación en general, y la mediación cooperativa en particular es "un instrumento de paz, solidaridad y unión» ${ }^{36}$.

De tal modo, proponemos la necesidad legislar procesos no contenciosos de mediación como parte de cualquier nueva legislación para fomentar las cooperativas de trabajo y fomentar otros métodos informales de resolución de disputas, cuando sea necesario adjudicar controversias por terceros.

Lo anterior no desdice de la importancia de que, como parte de su autogestión, los trabajadores adopten mecanismos que permitan garantizar el cumplimiento efectivo de cada cual con sus respectivas responsabilidades para con el colectivo. Al respecto, hay autores que enfatizan la importancia dentro de las CTA de la necesidad de poder lidiar satisfactoriamente con el elemento del aprovechamiento indebido («free riding») que permite a algunos efectuar el mínimo esfuerzo y aún así beneficiarse del resultado general de la operación. Ese tipo de conducta ha sido argumentada como uno de los principales elementos que ha impedido históricamente el desarrollo de empresas de trabajo asociado ${ }^{37}$. Por ello, el estatuto debe permitir formas justas y equitativas de medir el patrocinio que los propios trabajadores tengan a bien establecer, y que les permita lidiar con ese tipo de conductas nocivas.

La naturaleza íntima del vínculo entre los miembros de una cooperativa de trabajo también requiere flexibilizar los requisitos para su formación y para la aceptación de nuevos socios, a los fines de garantizar que cuentan con una capacitación adecuada que les permita interactuar como parte de un colectivo, con todas las responsabilidades que

36 Ordeñana Gezuraga; idem. p. 118.

37 Schwartz, Justin; idem. 
ello plantea en ese contexto particular. Volver a establecer mediante legislación requisitos básicos de capacitación y estudios de viabilidad, posiblemente sean consideraciones importantes en una ley que pretenda atender de forma especial al cooperativismo de trabajo. La educación continuada de estos aspectos entre los socios, debe también ser un factor fundamental, con miras a mantener la cohesión del grupo y la perdurabilidad de las CTA.

De lo que no debe de quedar dudas es de que la estructura jurídica de las cooperativas bajo la Ley 239, no cuenta con todos los elementos necesarios para atender el aspecto central de las CTA que es precisamente la prestación de trabajo; esencia del acto cooperativo en estas. Las estructuras de participación por delegación y la figura del principal ejecutivo establecidas en la Ley 239, no satisfacen adecuadamente las necesidades operacionales de las CTA, las cuales no solo requieren mecanismos participativos permanentes y directos, sino también de un menor grado de delegación de responsabilidades al principal ejecutivo. Ello, a los fines de superar el modelo de trabajo autoritario y enajenante del empresarismo capitalista. A los fines de transformar las condiciones del trabajo asalariado discutidas anteriormente, no basta con que los trabajadores tengan derecho a repartirse los resultados económicos de la empresa, así como el de elegir representantes en el gobierno de la entidad; sino que se deben promover estructuras de gobierno mas representativas y participativas. Por ejemplo, proveer para el establecimiento de comités regulares sobre aspectos esenciales a la organización del trabajo, la capacitación de trabajadores, la concesión de licencias y beneficios, o la implantación de medidas disciplinarias. La toma de decisiones sobre elementos centrales al concepto de la prestación del trabajo no puede mantenerse estructurada de la forma en la cual se reconocen actualmente en la ley 239. Recordemos que en el contexto del cooperativismo de consumo el trabajo permanece siendo otro factor de producción y se brinda a través del contrato de empleo. Por lo tanto, los modelos establecidos en esa legislación sobre administración del personal de la cooperativa no resultan viables ni propios en el contexto de una CTA que persigue superar las condiciones características del trabajo asalariado. Se requiere una ley que devuelva al conjunto de los trabajadores el control, conocimiento y satisfacción sobre el trabajo de las cuales son privados en las empresas capitalistas bajo el contrato de empleo. Una verdadera legislación sobre cooperativas de trabajo debe fomentar un tipo de relaciones de producción totalmente distintas donde se promueva no solo el control sobre el fruto de su trabajo a los trabajadores, sino también el que se generen relaciones de dominio sobre su capacidad productiva y que permitan que la actividad 
laboral se desarrolle en contextos de fomento al crecimiento personal, profesional y técnico de los empleados en ambientes inclusivos.

En ese sentido, deben revisarse también los modelos de medición de resultados utilizados por las cooperativas de consumo, pues en el contexto de las CTA la mera medición de los resultados finales puede resultar incompatible con la promoción de otros beneficios al trabajo que regularmente no son medidos, o no entran a formar parte de los criterios de eficiencia o productividad. Ciertamente las CTA tienen que poder medir resultados y tener economías netas positivas, pero esa medición tiene que incorporar elementos o parámetros sobre la satisfacción de los trabajadores, crecimiento profesional, beneficios solidarios, estabilidad laboral, control sobre su vida, y responsabilidad social, entre otros. Si en las CTA el servicio ofrecido por la cooperativa al socio es un puesto de trabajo, ese puesto de trabajo tiene que ser en su naturaleza un puesto de trabajo distinto del que le ofrece una empresa capitalista. Ello se tiene que poder realizar en todos los órdenes que permitan superar las características del trabajo obrero discutidas anteriormente.

Otro elemento que hay que extirpar del ordenamiento cooperativo con respecto de las CTA es la aplicación de las leyes laborales a las mismas. El eximir a las cooperativas de trabajo de aquella legislación dirigida a regular las relaciones de trabajo en empresas donde existe el elemento de dependencia ante el capital resulta fundamental. La aplicación de la legislación laboral a las cooperativas de trabajo atenta contra la naturaleza misma de éstas, pues regula desde afuera el elemento central de la asociación de los trabajadores en tales empresas y que constituye el acto cooperativo mismo desde el punto de vista jurídico. Cualquier nueva legislación sobre cooperativas de trabajo debe dejar este elemento claramente establecido, de cara al nuevo tipo de relaciones de producción que debe generar esta clase de empresarismo solidario. Ello, no obstante, no debe ser óbice para que las CTA puedan acogerse voluntariamente a los beneficios de la legislación del trabajo cuya finalidad sea el establecimiento de seguros o planes de beneficios, ni para que se les deje de requerir cumplimiento con aquellas otras relacionadas a proteger la salud y seguridad ocupacional.

Finalmente, hay que ser cuidadosos en que la figura de las CTA no se utilice para encubrir relaciones de dependencia y subordinación laboral, particularmente en lo relativo a la contratación de empleados a quienes no se les garantice el derecho de formar parte de la cooperativa. Cualquier legislación al respecto debe establecer con claridad cuáles serían las circunstancias específicas en las cuales, a manera de excepción, se podría permitir el trabajo no asociado dentro de una CTA, así como los periodos máximos durante los que se permitiría. Contrario a la 
Ley 239 que no regula el trabajo asalariado dentro de las CTA, ni le impone límites; en una nueva ley se debe establecerse que el trabajo no asociado únicamente debe permitirse de forma temporal y en casos de excepción para atender aumentos cíclicos de la demanda o cubrir licencias de trabajadores asociados. Al respecto, nuestra ley es claramente inadecuada pues permite el absurdo de que existan CTA en las que sus socios se limitan a un grupo restricto de fundadores, que entonces emplean al grueso de los trabajadores en circunstancias de dependencia y subordinación, a veces en números muy superiores. Igualmente se debe legislar para que las CTA no puedan utilizarse como medio de intermediación laboral, mediante el cual se externalicen ciertos puestos por una empresa que debieran formar parte de sus operaciones integradas, creando supuestas CTA que en realidad carecen de control autónomo.

Relacionado con lo anterior, debe ponderarse detenidamente cómo el modelo de CTA aplicaría en el contexto de sociedades profesionales. En cuanto a este, entendemos que debemos tener cuidado con que, al permitirse las cooperativas de profesionales, éstas no se conviertan en un mecanismo para evadir el pago de sus obligaciones fiscales por personas que no operan como parte de una empresa integrada. También habría que considerar establecer condiciones para que los profesionales no continúen subordinando el trabajo de otros componentes básicos de sus empresas, excluyéndolos de la membresía o utilizando mecanismos de subcontratación o externalización. Por ejemplo, en el modelo de las Corporaciones Propiedad de Trabajadores (PT) contenido al capítulo 16 de la Ley General de Corporaciones de Puerto Rico ${ }^{38}$, se requiere establecer unos topes de remuneración que restrinjan las diferencias entre las compensaciones de aquellos trabajadores que menos ganan y los que por la naturaleza de su trabajo ganan mas. La incorporación de ese tipo de mecanismos en una nueva legislación sería fundamental para evitar el aprovechamiento indebido de las CTA para ocultar operaciones tradicionales de sociedades profesionales y de otros tipos.

Otros aspectos relacionados al modelo legal existente de CTA en Puerto Rico que debe ser revisado en el contexto de una nueva ley es el asunto de la forma de pago del interés limitado del capital y sus repercusiones en cuanto a una empresa de naturaleza productiva. En las CTA el capital lo proveen fundamentalmente los socios en condiciones en las que ese capital no tendrá un derecho a adjudicarse los beneficios de la producción. En ese sentido, es necesario contar con

3814 LPRA 3871.

Boletín de la Asociación Internacional de Derecho Cooperativo 
disposiciones suficientes para que ese capital pueda ser remunerado al menos en condiciones iguales a las que generaría esa aportación dineraria para los trabajadores de haberla invertido fuera en el mercado monetario, es decir que se concretice un pago efectivo por ese alquiler. Actualmente, el beneficio pagado al capital tiene la característica de ser mas bien un dividendo que se paga de los sobrantes de la operación, por lo que realmente no constituye un pago fijo. El capítulo sobre finanzas de las cooperativas contenido en la Ley 239 debe ser revisado como parte de cualquier proceso para establecer nueva legislación aplicable específicamente para las CTA. Al respecto, recomendamos que se estudie el mecanismo de las cuentas individuales de capital utilizadas por la legislación de las PT, como modelo alternativo a esos efectos. Este sistema permite atender el asunto de la transición entre socias que se retiran y el ingreso de nuevas trabajadoras frente a la acumulación de capital de las primeras, para que la ausencia de capital de las segundas no impida el que puedan convertirse en trabajadoras asociadas. Además, establece un exitoso mecanismo para el autofinanciamiento de la cooperativa y el problema de falta de acceso a capital debido a su naturaleza no capitalista ${ }^{39}$.

Sometemos también que, en el contexto de las cooperativas de trabajo, debe repensarse el modelo regulatorio que actualmente existe en Puerto Rico, a los fines de determinar si es correcto el que las mismas sean supervisadas y fiscalizadas en su operación por la Corporación para la Supervisión y Seguro de las Cooperativas (COSSEC), agencia regulatoria del sector ahorro y crédito. Entendernos que al presente existe una confusión doctrinal respecto del papel del Estado en la fiscalización de las cooperativas de tipos diversos ${ }^{40}$. Ciertamente la supervisión estatal del empresarismo cooperativista se justifica en función de la reglamentación gubernamental de aquellas industrias en las que puedan operar ciertos tipos de cooperativas, tales como las industrias financieras y de seguros. Sin embargo, nos parece impropio en que en nuestro ordenamiento se insista en regular a las cooperativas de trabajo y otras de tipos diversos exclusivamente por su estructura de negocios de forma cooperativa cuando la ley pregona expresamente lo contrario. De otra parte, institucionalmente COSSEC no parece estar dispuesta a reconocer las limitaciones a su función fiscalizadora surgidas en 247 de 2008 con respecto del cooperativismo de tipo diverso.

39 Véase Ellerman, op. cit.

40 Colón Morales, Rubén; El Principio de autonomía cooperativa frente al Estado: su articulación bajo la legislación de Puerto Rico; 48 Boletín de la Asociación Internacional de Derecho Cooperativo, p. 177 (2014). 
Por lo tanto, cabría considerar la deseabilidad de que cualquier ley nueva que pueda ser proponer para fomentar las CTA exima a éstas de tener que someterse a las fiscalización y control de COSSEC, particularmente cuando se trata de una entidad cuyo fin primordial es regular la industria del cooperativismo de ahorro y crédito, que es un cooperativismo de consumo con características muy distintas en cuanto a su operación cotidiana.

En todo caso, cualquier supervisión del Estado para garantizar que las cooperativas de trabajo cumplen con su propósito de ser empresas que operan al margen del contrato de empleo y de forma democrática y solidaria por parte de los trabajadores asociados, debía recaer en el Departamento del Trabajo y Recursos Humanos de Puerto Rico. Lo anterior, limitado a fiscalizar que bajo el manto cooperativo del trabajo asociado no se escondan relaciones de dependencia y subordinación como las existentes bajo los contratos de empleo; así como para proveer servicios de mediación, arbitraje.

Finalmente, convendría incorporar elementos para el fomento de las CTA, incluyendo los beneficios contributivos existentes para otras cooperativas. También cabría incluir incentivos para que los dueños de negocios vendan sus empresas a los trabajadores (tales como reducciones en las tasas sobre ganancias de capital); legislación para dar una primera opción a los trabajadores sobre empresas que vayan a cerrar, así como preferencias en la contratación gubernamental de servicios, o en la privatización de corporaciones públicas.

\section{Conclusión}

Como hemos visto, la naturaleza particular de las CTA requiere de una normativa legal separada de aquella conceptualizada para regir el cooperativismo de consumo. Ello así, pues ni los principios cooperativos se manifiestan de igual forma, ni las estructuras de gobierno y administración, ni las disposiciones sobre de finanzas contenidas en nuestra Ley 239 se ajustan adecuadamente al modelo de negocios de las CTA. Para viabilizar su mas pleno desarrollo hace falta una legislación separada, específicamente diseñada para adaptarse a las particularidades del cooperativismo de trabajo y a la naturaleza específica de la relación capital trabajo que se da dentro de las mismas. En consideración a lo anterior es que hacemos estas propuestas sobre los elementos que deben ser considerados a la hora de proponer nueva legislación específicamente diseñada para favorecer el cooperativismo de trabajo asociado en Puerto Rico. 


\section{Bibliografía}

ARANA LANDÍN, Sofía. 2019. "Estudio del marco jurídico de referencia para las cooperativas de trabajo asociado en los EE.UU.: Una propuesta de regulación a nivel federal». Boletín de la Asociación Internacional de Derecho Cooperativo, n. ${ }^{\circ} 54$ (julio), 19-54. https://doi.org/10.18543/baidc-542019pp19-54.

BATTILANI Y SCHORTER. 2012. The Cooperative Business Movement: 1950 to the Present; Cambridge University Press, USA.

BIRCHALL AND KETILSON. 2009. Resilece of the Cooperative Business Model in Times of Crises, International Labor Organization.

BROWN, Wendy. 2015. Undoing the Demos: Neoliberalism's Stealth Revolution, Editorial Zone Books, New York, USA.

BUSTAMANTE, A.M. 2019. "Gestión humana socialmente responsable en cooperativas de trabajo asociado colombianas», CIRIEC-España, Revista de Economía Pública, Social y Cooperativa, 95, 217-255. DOI: 10.7203/ClRIEC-E.95.10433.

CÁTALA, Francisco. 1996. Democracia Obrera: ¿Autogestión o Privatización?; Ediciones Huracán, San Juan, Puerto Rico.

COLLAZO, Fernando. 2018. La Economía del Autogestionismo Empresarial: Competitividad, Solidaridad y Democracia en la Era de la Globalización. Editorial Impresive Publications LLC, Puerto Rico.

COLÓN MORALES, Rubén. 2014. «El Principio de autonomía cooperativa frente al Estado: su articulación bajo la legislación de Puerto Rico. Boletín de la Asociación Internacional de Derecho Cooperativo, núm. 48. DOI: https://doi.org/10.18543/baidc-48-2014pp177-190

COLÓN MORALES, Rubén. 2018. "La ruta autodestructiva del cooperativismo de vivienda puertorriqueño: el problema de la pérdida de la identidad cooperativa mediante la transformación de valores de uso en valores de cambio». Boletín de la Asociación Internacional de Derecho Cooperativo, n. 52 (julio), 19-46. https://doi.org/10.18543/baidc-52-2018pp19-46.

DHAL, Robert, A. 1990. A Preface to Economic Democracy; University of California Press; USA.

ELLERMAN, David. 1990. The Democratic Worker - Owned Firm: A New Model For East and West; Unwin Hyman Publications; London.

FAJARDO GARCÍA (Coordinadora). 2015. Empresas Gestionadas por sus Trabajadores Problemática Jurídica y Social; Ed. CIRIEC España.

GARCÍA MÜLLER, Alberto. 2012. Instituciones de Derecho Cooperativo y de la Economía Solidaria; Editorial Académica Española: Alemania. Tomo I.

GOULD, C.C. 1998. Rethinking Democracy. Cambridge University Press, New York.

HERNÁNDEZ PERLINES, Felipe. 2010. "La Economía Social, análisis de un sector empresarial», en La Economía Cooperativa como Alternativa Empresarial, Ediciones de la Universidad de Castilla La Mancha, España.

MESA MEJíAS, María del Pilar. 2019. "Las relaciones entre los sujetos del sector no estatal cubano: el socio-trabajador por cuenta propia en las coo- 
perativas no agropecuarias». Boletín de la Asociación Internacional de Derecho Cooperativo, n. ${ }^{\circ} 54$ (julio), 131-44. https://doi.org/10.18543/ baidc-54-2019pp131-144.

MOIRANO, Armando Alfredo. 2010. Manual de Cooperativas de Trabajo; Editorial Lajouane; Buenos Aires, Argentina.

ORDEÑANA GEZURAGA, Ixusko. 2012. "Mas allá del arbitraje cooperativo: la mediación cooperativa. Sobre la necesidad de fomentarla en el ordenamiento jurídico español a la luz del Real Decreto-Ley 5/2012, de 5 de marzo, de mediación en asuntos civiles y mercantiles»; GEZKI núm. 8.

PARENTI, Michael. 2011. Democracy for the Few, Editorial Wadsworth Cenage Learning, USA.

PENCAVEL, John H. 2013. The Economics of Workers Cooperatives; Editorial Edward Elegar Publishing Limited; Great Britain.

PEINADO GRACIA Y VÁZQUEZ RUANO. 2013. Tratado de Derecho de Cooperativas, Ed. Tirant Lo Blanch, Valencia.

PINTO, Sanjay. 2010. Ours To Share: How Worker- Ownership Can Change the American Economy; Surdna Foundation; https://philantropynewyor.org/sites/default/files/resources/OursToShareWeb1.pdf.

RESTAKIS, John. 2010. Humanizing the Economy: Cooperatives in the Age of Capital, Editorial New Society Publishers, Canada.

SUÁREZ, María Florencia. 2020. «Los trabajadores de la economía popular y la garantía de sus derechos laborales». Boletín De La Asociación Internacional De Derecho Cooperativo, n. ${ }^{\circ} 56$ (abril), 157-68. https://doi. org/10.18543/baidc-56-2020pp157-168.

SHUARTZ, Justin. 2012. "Where Did Mill Go Wrong?: Why the Capital-Managed Firm Rather than the Labor-Managed Enterprise Is the Predominant Organizational For in Market Economies». Ohio State Law Journal. Núm. 73.

VERÓN, Alberto V. 2009. Tratado de las Cooperativas; Editorial La Ley; Buenos Aires, Argentina. Tomo III.

WINKLER, Adam. 2018. We the Corporation: How the American Businesses Won Their Civil Rights, Liveright Publishing Co., New York, USA.

WOLFF, Richard. 2012. Democracy at Work: A Cure for Capitalism; Editorial Heymarket Books; Chicago, USA. 


\section{Derechos de autor}

El Boletín de la Asociación Internacional de Derecho Cooperativo es una revista de acceso abierto lo que significa que es de libre acceso en su integridad inmediatamente después de la publicación de cada número. Se permite su lectura, la búsqueda, descarga, distribución y reutilización legal en cualquier tipo de soporte sólo para fines no comerciales y según lo previsto por la ley; sin la previa autorización de la Editorial (Universidad de Deusto) o el autor, siempre que la obra original sea debidamente citada (número, año, páginas y DOI si procede) y cualquier cambio en el original esté claramente indicado.

\section{Copyright}

The International Association of Cooperative Law Journal is an Open Access journal which means that it is free for full and immediate access, reading, search, download, distribution, and lawful reuse in any medium only for non-commercial purposes, without prior permission from the Publisher or the author; provided the original work is properly cited and any changes to the original are clearly indicated. 